\title{
What Modifies the Expression of Personality Tendencies? Defining Basic Domains of Situation Variables
}

\author{
Gerard Saucier, ${ }^{1}$ Tarik Bel-Bahar, ${ }^{1}$ and \\ Cynthia Fernandez ${ }^{2}$ \\ ${ }^{1}$ University of Oregon \\ ${ }^{2}$ California State University, San Bernardino
}

\begin{abstract}
A taxonomy of personality-relevant situations will provide a valuable complement to the taxonomy of personality attributes. To identify some of the most important modifying factors, we asked laypersons what modifies expression of their own traits. Spontaneously generated situation descriptors were elicited from 77 university students, leading to over 7,000 reports of situations. We determined the most frequently occurring words and phrases, and developed initial classification categories. Next, we tested the reliability of the categories, and made refinements to focus on those that proved most reliable. Based on results, we propose that situation descriptions involve at least four separable broad domains of variables-locations, associations, activities, and passively experienced processes - each of which appears to have distinct linguistic markers.
\end{abstract}

Psychology has a longstanding custom of dividing the bases for human behavior into two kinds. Dispositional factors (traits or other constitutional tendencies including genetic ones) are commonly differentiated from environmental factors (external and situational conditions).

We are grateful to Gale Pearce, Kathy Hadjiyannakis and Brad Lytle for assistance with this research, and to Lewis R. Goldberg and Sarah E. Hampson for helpful suggestions on earlier drafts of the manuscript.

Correspondence concerning this article should be addressed to: Gerard Saucier, Department of Psychology, 1227 University of Oregon, Eugene. OR. 97403-1227. USA. Tel.: 541-346-4927. Fax: 541-346-4911. E-mail: gsaucier@uoregon.edu.

Journal of Personality 75:3, June 2007

(C) 2007, Copyright the Authors

Journal compilation (C) 2007, Blackwell Publishing, Inc.

DOI: $10.1111 / \mathrm{j} .1467-6494.2007 .00446 . x$ 
A complete understanding will take account of the complementary contributions of dispositional and environmental factors.

Personality psychology has made considerable progress toward identifying a relatively consensual taxonomy of personality traits (John, 1990). There is also increasing recognition of the need for a "taxonomy of situations" (Funder, 2001). The lack of a taxonomy of situations - of those contingencies that modify the expression of trait tendencies-impedes the understanding of personality, in several respects.

First, situations involve individual differences in important ways. If all individuals behaved with complete cross-situational consistency, or if all individuals were equal in how they changed their behavior in response to situations, then there would be no gain from linking trait and situation taxonomies. But there are probably substantial individual differences of several kinds: (a) in the degree of cross-situational consistency, (b) in the degree to which one kind of situation affects behavior, (c) in the kind of behavior that is affected by a given situation, and (d) in the set of situations that tend to facilitate one response versus another (e.g., one individual may be a "different person" depending on whether he is at work or at home, whereas another may differ according to whether she is in a large or a small group of people). Moreover, there should be individual differences in how often a given situation is encountered, based on individual choices. These choices may in turn be based on their traits and beliefs so that individuals come to inhabit primarily social worlds that fit their own dispositions (Ickes, Snyder, \& Garcia, 1997; Snyder, 1983). Investigation of all these kinds of individual differences will require as a prerequisite an identification of the most important situational factors.

The lack of a situation taxonomy impedes in other ways. Without being related to situations, traits lack nuance and appear to operate in a vacuum. Because traits represent behavior patterns that should generalize across a representative range of situations, a situation taxonomy might indicate a standard set of situations that might be represented in the range of items measuring any trait. A promising "conditional approach" to dispositions (Wright \& Mischel, 1987), to be assessed by situation-behavior profiles (Shoda, Mischel, \& Wright, 1994), has had its development limited by the lack of representative set of situations in which to sample behaviors. 
In this article, we report on empirical studies relevant to the task of creating a situation taxonomy. The task is complicated by considerable disagreement and ambiguity regarding how "situation" is defined, not to mention that regarding how "trait" is defined. In this article we employ an inclusive definition of traits - understanding them to represent stable tendencies toward any psychologically significant attribute. We also take a relatively inclusive approach to defining situations.

One way to construct a taxonomy of situations would be to treat experimental social psychology as a vast literature that identifies, in its largest and most replicable effects, situations with substantial behavioral effects. One could then catalog situations by a survey of this literature. Situations in this catalog would advantageously include many that are not obvious to laypersons. However, the catalog would reflect the content biases of social psychology, where the situations chosen for study depend on the potentially idiosyncratic foci of theories and of investigators in the field. A complementary starting point would be to ask laypersons what they find (or believe) moderates expression of their own personality tendencies. Lay accounts of what influences behavior patterns may have their own biases, but an advantage is that these accounts will likely span a broad range of potential causes, helping to ensure that from its start a situation taxonomy is suitably wide in its purview. The present study focuses on lay accounts, but ultimately, both behavior-based experimental and perception-based lay accounts are needed for a complete taxonomy (Magnusson \& Ekehammer, 1976).

\section{What Might Be the Critical Distinctions Among Situations?}

What should we expect laypersons to mention as modifiers of personality expression? A variety of aspects are discernible in psychological situations, and numerous authors have attempted to identify the most important such aspects (Bem \& Funder, 1978; Bowers, 1973; Endler \& Magnusson, 1976; Frederiksen, 1972; Funder \& Colvin, 1991; Furnham \& Argyle, 1981; Magnusson, 1981; Pervin, 1978). Recently, reviews of this literature have appeared (Forgas \& Van Heck, 1992; Ten Berge \& De Raad, 1999), although agreement on a widely accepted and comprehensive taxonomy of situations is yet to be achieved (Endler, 1993; Funder, 2001; Hogan, Harkness, \& Lubinski, 2000; Johnson, 1999). 
A brief survey might well begin with Lewin and Murray. Lewin's (1936) concept of "life space" included regions defined by work, school, church, and family, and so on. Although Lewin conceived also of inner-personal and imaginary regions, the regions in an individual's life space involved mostly physical and social environments. Murray (1938) developed the concept of "press," an impactful directional tendency or potency in an external object or environment with which humans have contact. Building on distinctions made by Kantor (1924) and Koffka (1935), Murray distinguished "beta press"- what the press is in the subject's own interpretation, an interpretation that may profoundly affect behavior-from "alpha press," a more objective account of the milieu as it might be seen by an impartial scientific observer.

According to a rational analysis by Pervin (1978), people usually describe situations in terms of associated locations (Where?), other people (Who?), activities (What/Why?), and times (When?). For example, a birthday party may occur in a house (where), with family and friends (who), to celebrate and enjoy and eat cake (why), during the evening (when). However, construals of the situation can be very different from person to person. Each person at the party will be attending to different aspects of the situation, and each aspect may carry a different meaning for different people. For example, one child at the party could feel jealousy instead of happiness during the birthday celebration, while an adult who is present could experience the birthday party as a tedious child-care responsibility.

This example brings out an important distinction with respect to situations. For a given physical and social situation, there is an important distinction between general consensual knowledge (e.g., it is a birthday party) and subjective knowledge (e.g., it involves my taking care of children). Subjective situation features have become increasingly prominent in contemporary studies of situation dimensions (Forgas \& Van Heck, 1992). Van Mechelen and De Raad (1999, p. 334) note that "An integrative account of personality clearly implies the need to go beyond general contexts in which behavior occurs" and that, indeed, "situations are to be characterized in terms of their psychological features, including various subjective situation characteristics."

Previous investigators (Cantor, Mischel, \& Schwartz, 1982; Endsley, 1995; Magnusson, 1971; Pervin, 1978; Van Heck, 1984, 1989; 
Zwaan \& Radvansky, 1998) have provided a variety of classifications of types of situation information. In this article we rely primarily on the classification of Block and Block (1981), which provides, in our view, the strongest and most comprehensive rational division among situations. This classification divides situation features into three basic levels (environmental/physical, canonical/consensual, and functional/subjective):

1. Environmental or physical-biological features of the situation are the most objective and observable features of our environment. Perhaps because of this, they are the most prototypical situations. They are shaped by the biological structure of human perception as determined by evolution (Block \& Block, 1981). Characteristically, these kinds of features should be readily (we might say, objectively) observable via machines. A floodplain, a city street corner, physiological arousal, or sleeping - all these could be considered objectively observable physical-biological features. To reference such features, other classifications have used labels like locations, environments, settings, and places.

2. Consensual or canonical features of the situation are composed of shared or commonly-held group knowledge. A party, a funeral, an argument, or a fraternity initiation - these situations are called what they are based on a substantial element of group consensus. For example, everyone at a funeral presumably agrees that it is a funeral and not a party, and thus has their behavior moderated in a similar way. This kind of knowledge is represented in the lexicon of a group, reflecting shared concepts, shared behaviors, and the shared meaning given to those behaviors. Canonical features build upon physicalbiological situation features, but overlay these basic features with specific culturally and group-derived perceptions. Situation types labeled as people and activities in other classifications involve canonical features, which are less observable than physical-biological features, but more observable than the next level of situation features.

3. Functional or subjective features of the situation do not necessarily involve group-shared knowledge; they are "what the individual refers to and nothing else" (Block \& Block, 1981, p. 87). Such features are referenced in statements like "I was feeling 
tired," "that person reminds me of my father," "I feel the presence of God in that church," or "I'm not myself when I'm with you." It makes sense to call these features "functional" because they are often those aspects of the situation that are most salient to the individual perceiver and most related to their behavior, a point Mischel and Shoda (1999) make with respect to their own similar class of situations labeled "psychological/subjective."

Physical observability versus subjectivity is the most crucial dimension that differentiates these three levels of situation features. Some situations predicated of a person (e.g., in church, dressed up, mowing the lawn) are easily observed by others, whereas other situations (e.g., being myself, not getting what I want) are, due to their more subjective nature, more difficult for others to observe. Competing definitions of "situation" vary in large part according to whether one admits only the most static and prototypical (i.e., physical-biological) level of situations, or goes all the way to include consensual/ canonical and even subjective/functional features.

An important caution regards the discreteness of these three levels. Although in some instances of situation-perception one level may predominate, in other instances these three levels may be combined. Canonical features are overlaid on environmental features, whereas functional/subjective features are overlaid on the other two types of features. Moreover, at any point in time, a feature that is environmental may be linked to a consensual or a functional feature. For example, an individual could use a consensual interpretation (e.g., this is a sacred place) about an environmental/physical feature (a cathedral, temple, mosque, or revered mountain) but engage in an action based on a subjective construal (a goal that one has in mind, for which one prays in the sacred place). This kind of interchangeability is similar to findings from studies of language comprehension (Zwaan \& Radvansky, 1998), where different features of the situation (e.g., objects, persons, goals) naturally become more prominent, or activated, depending on their usefulness to the reader.

As a further illustration, Table 1 presents an example of a group of domino players in a small Italian café in New York City, with the situation broken up in various ways, going from more general and observable features to highly subjective features. Readers are invited to imagine themselves as a roving eye that can examine any part of the 


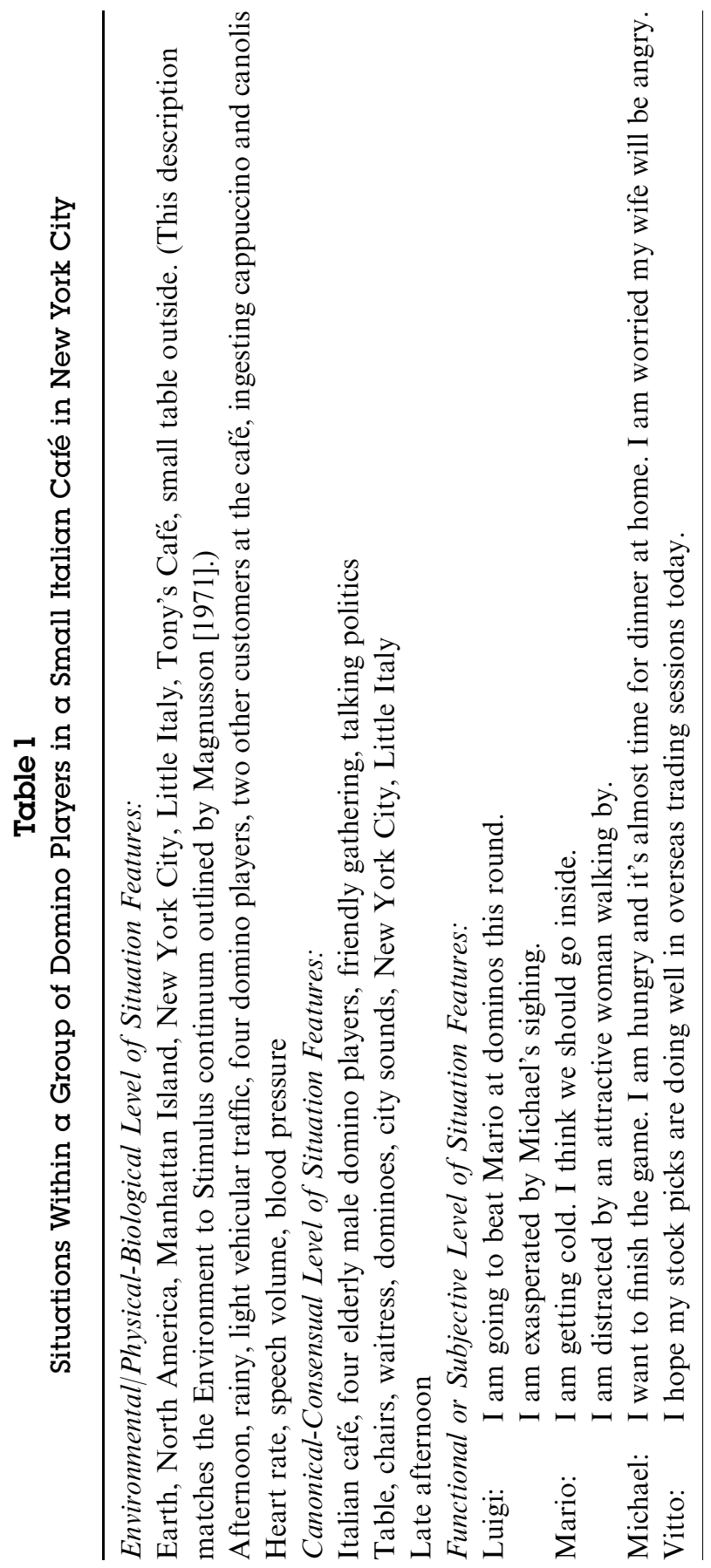


situation, from a bird's eye view, or an inside-the-head view. At each viewpoint, the roving eye may notice different features of the situation as delineated in Table 1. This example serves to illustrate that a situation has multiple levels and can be viewed from many perspectives.

\section{The Role of Traits in Constructing Situation Taxonomies}

What is the role for personality attributes in situation taxonomies? It is widely recognized that traits predict behavior to some degree, and that broad traits predict broad categories of behavior. Traits can take both cross-situational and situation-specific tendencies into account (Funder, 2001; Johnson, 1999; ten Berge \& De Raad, 1999). Traits include situational and behavioral probabilities, and contain information about situation contexts that allow for the expression of that relevant behavior (Funder, 2001; Johnson, 1999). As Johnson (1999) reminds us, low cross-situational consistency does not reduce the power of broad personality constructs such as the Big Five, because consistency on a trait can mean only behavioral consistency within trait-relevant sets of situations.

In most cases, the abstracted trait impressions we have about others are built up from specific situational and behavioral information. As we move from acts to dispositions (or traits), we go from a subordinate to a basic level of categorization (Buss \& Craik, 1983). As we move up the trait hierarchy, the traits subsume a greater number of distinct acts in relevant situations. Traits can be measured more narrowly through explicit constraining of personality descriptions with situational information (e.g., Revelle, 1995; Van Heck, Perugini, Caprara, \& Froeger, 1994; ). Persons may activate observable and consistent behavior only under conducive circumstances, and understanding these conducive circumstances or situations (as well as the non-conducive ones) for trait expression is crucial for building better models of behavioral prediction (ten Berge \& De Raad, 2002). A problem is that when situations are referenced, it is probably a non-representative sampling of situations, although there is no basis yet for deciding that a set of situations is representative.

The foregoing review suggests several desiderata for studies that might lead to a taxonomy of situations. We should be attentive to the level of situation description that is favored either in the selection of variables or in the methodology. The relative observability versus subjectivity of the situation variables bears examining, and may be 
diagnostic of the level of description being employed. A relatively comprehensive taxonomy of situations should, however, include variables at multiple levels. Some researchers may find it more prudent to restrict their operational definition to the most prototypical situations (i.e., static physical-biological features), while others may extend their purview to include also the consensual/canonical level of socially defined situations (as in Sells, 1963; Snyder, 1983), and some may go even farther and include the subjective/ functional level. But a "multi-level taxonomy" will be optimal because it will allow integration of work addressing all levels of situation features.

Accordingly, if we are to delineate the broad outlines of an adequate taxonomy of situations, it is advantageous to begin with an inclusive, open-ended approach to identifying variables, a strategy that would not limit us to one level of situation description. Situations should be allowed to include environmental/physical, consensual, and subjective features; there is no reason to exclude any of these a priori. An open-ended task is appropriate. Rather than asking respondents to think in general, across all traits, it is more useful to present a variety of traits and attributes. Then one can try to facilitate laypersons' retrieval of the extreme conditions under which a trait that is not usually expressed is more likely to be expressed, or in which a trait one usually has is especially unlikely to be found. The study that follows is based on such an approach.

\section{METHOD}

\section{Participants}

Participants were 77 college students from a California state university that included substantial minorities of Hispanic, African-American, and Asian background, making it fairly demographically representative of the United States population. Participants were recruited from undergraduate psychology classes and received credit toward course requirements for their participation. Substantial numbers of students at this university (and in this sample) were adults with considerable work experience, in many cases in evening classes with full-time jobs.

\section{Materials}

Participants were presented with a sentence-completion task that involved two forms, each of which listed the same 50 adjectives followed by the 
word "when" (e.g., Emotional when, Persistent when). On one form, the words were listed under the heading "I'm MOST LIKELY to be ...," and instructions were to write in a way that would complete each of 50 sentences (e.g., "I'm most likely to be emotional when __,", "I'm most likely to be persistent when __"). On the other form, the words were listed under the heading "I'm LEAST LIKELY to be ...," and instructions were to write in a way to complete each of 50 sentences (e.g., "I'm least likely to be emotional when __," "I'm least likely to be persistent when __"). The order of the two forms was counterbalanced across participants.

In order to garner a wider range of responses, not eliciting only those situations that provoke extremes, an alternate version of the questionnaire was employed with half the participants instead of the first version. In the second version of the questionnaire the same 50 adjectives were listed on one form under the heading "I'm VERY LIKELY to be ..." and again on the other form under the heading "I'm VERY UNLIKELY to be ..."

In either version, the forms were labeled as a "Likely Sentences Questionnaire," to encourage participants to conceive of the task as coming up with natural-sounding ways of completing the sentences. Participants were asked to fill in the blank after each adjective with the best or most appropriate phrase, describing a specific situation. The open-ended response format allowed for situations at any of the three levels (Environmental, Consensual, Subjective) to emerge relatively easily without any being overtly favored over the other.

Additionally, participants were also asked to rate the accuracy of each of their responses on a 4-point scale, ranging from (1) Not Very Accurate to (4) Very Accurate. This was a measure of how accurate they believed a particular attribute to be for them in the specific situation that was chosen. Because virtually every participant gave the highest (4) accuracy rating to every one of their responses, no further use was made of these accuracy ratings.

The 50 adjectives were derived from data on a set of 500 most frequently used English person descriptors (Saucier, 1997), by the following procedure: Self-ratings by 700 members of an adult community sample and ratings of liked peers by 201 college and community college students using these 500 descriptors were pooled. The correlations among these 500 variables were used as indices of their distance from each other, and they were agglomerated into clusters using a hierarchical average linkage (between-groups) algorithm. One term was systematically sampled from each of 50 major clusters and regions of the dendrogram. (A list of the 50 terms, which can be considered a reasonably representative set of familiar English adjectival person-descriptors, is available from the 
first author upon request.) The terms included a wide variable selection, not being limited, for example, to variables strongly associated with the Big Five.

Once responses were gathered, our plan was to develop a clustering scheme for commonly mentioned situations. We planned then to test the reliability of this scheme among an independent set of judges.

\section{RESULTS}

Table 2 presents the most commonly mentioned situations among the 7,272 total readable responses obtained (of the total 7,700 response blanks, 428 [5.5\%] were either not filled in or not readable). The table lists the situations in descending order by frequency of mention, with specific frequency noted in parentheses. All terms or phrases mentioned in at least 10 responses are included in the table. As can be seen, frequencies for obviously synonymous or antonymous descriptions (e.g., sad-depressed, happy-unhappy) are aggregated. The four columns group the responses according to the most intuitively obvious set of categories: whether they represent locations, subjective states, interpersonal associations (who one is with), or a fourth column provisionally labeled as "actions and positions."

Three of these classes have some correspondence with the three levels of situation features described earlier. Subjective states may be examples of situations emphasizing the subjective (or functional) features as described earlier. Interpersonal associations refer to whom - if anyone - one is with. These can be understood as major elements in the consensual-feature category: Who is a stranger, a friend, or a family member is not an obvious objective feature, but it is consensually understood by the parties in the interaction. Locations can be considered a primary constituent of the environmental-feature category. The most commonly mentioned locations were those of home, school, or work, each of which implies some kind of social role (likely to involve consensual and even subjective features).

Subjective states were mentioned with surprisingly high frequency. The 52 most frequently mentioned situations accounted for 1,919 or $26 \%$ of the total number of responses, and nearly half (24 of 52) can be considered subjective states (e.g., angry, feeling good, confident). This indicates that laypersons' perception of 


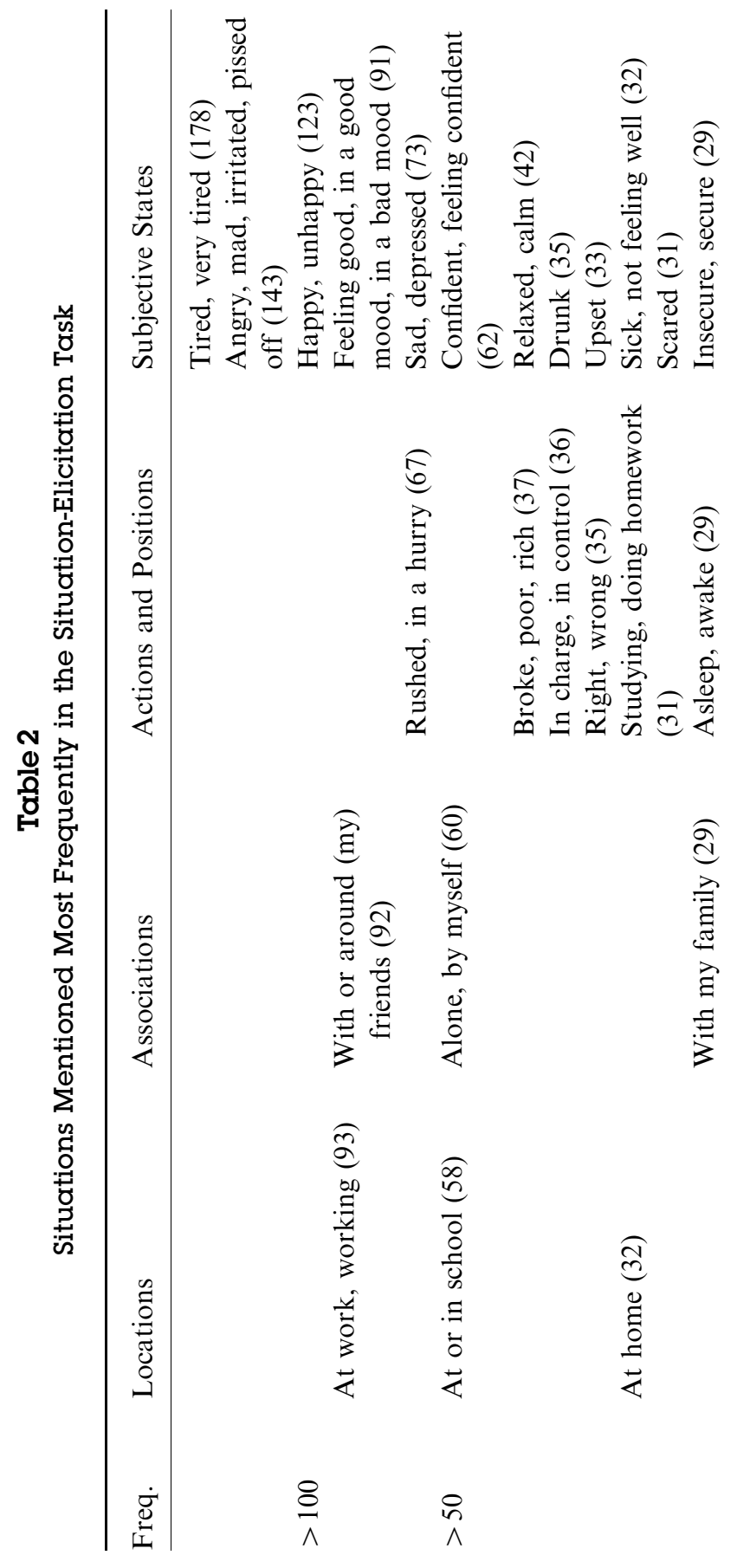



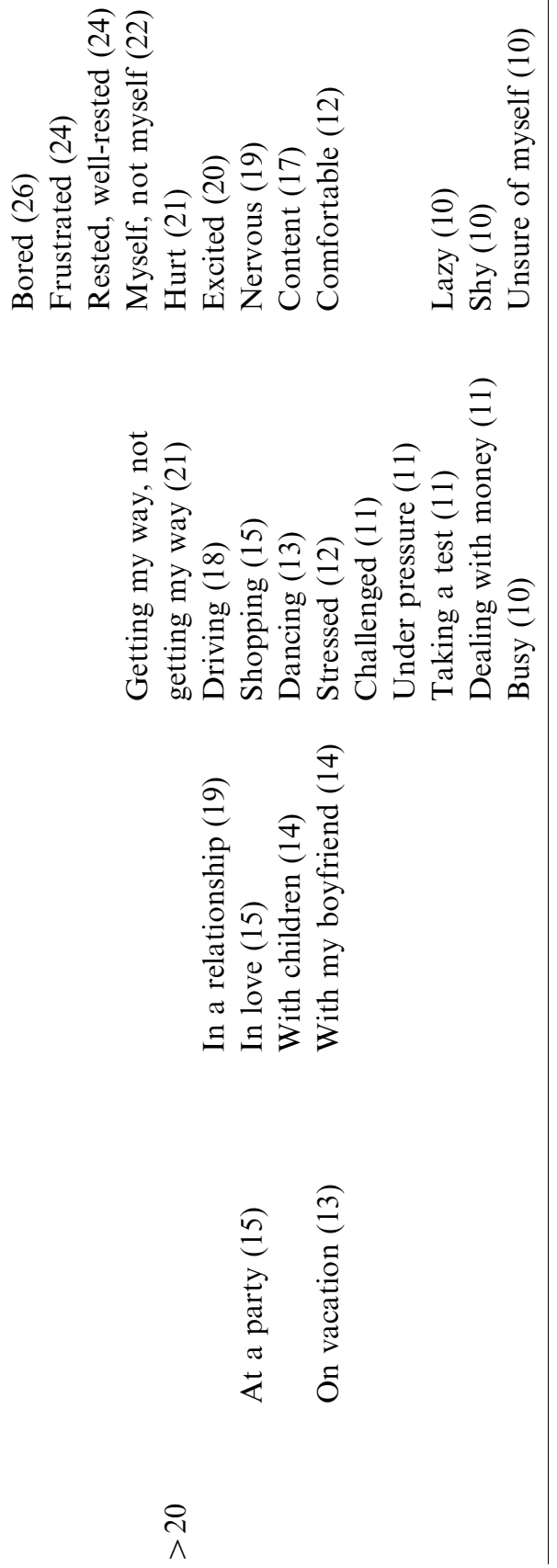
influences on their own traits have a distinct focus on subjective features, and a special emphasis on mood states.

Table 2, of course, is insufficient as a taxonomy of situations. The situations listed in the table do likely reflect widely shared lay concepts of modulators of the expression of a person's behavioral tendencies. However, 52 situations is not a very parsimonious representation. Some of these 52 are closely related to one another, and could be combined into broader groupings. Just three groupings (subjective states, locations, and interpersonal associations) is probably too few, and it is difficult to fit the responses in the "Actions and Positions" column into these three. In addition, the 52 groupings directly reflect $26 \%$ of the situations mentioned in the study, but not the other $74 \%$. There may be types of situations that are commonly mentioned but without certain high-frequency phrasings like those found in Table 2.

Next, we made an initial attempt to create a more comprehensive taxonomy, beginning with the data obtained in Study 1. The goal was to find a set of more specific categories that could be used in a reliable manner by independent judges.

From the original $(>7,000)$ responses, two subsets of approximately 1,000 responses each were identified by stratified sampling, selecting every seventh response from the entire data set. Each 1,000response subset was classified by a researcher (either the first or third author). Specifically, each response was printed on a separate small paper card, and the researchers sorted the 1,000 cards into their own intuitively derived clusters. The two independent clusterings were then compared, and the common features became the basis for a candidate classification system, with sixteen common categories: Physical Locales, Relational Contexts, Affective/Emotive States, Motivational (Goal-Seeking) States, Goal-Realization States, Cognitive States, Activities, Transaction-Dependent or Transactional Contexts, Sleep-related Contexts, Conditions of Crisis and Danger, Conditions of Time-Pressure, Conditions of Finance, Conditions of Dress, States of Identity-Realization, States of Expressing Another Trait, and Miscellaneous.

"Physical locales" corresponded closely to the "locations" column from Table 2, and "relational contexts" to the "interpersonal associations" column. In this candidate classification system, however, "subjective states" was provisionally subdivided into four more specific categories - affective/emotive, motivational, goal-realization, 
and cognitive states. There is also a partially subjective-state character to some other categories, including conditions of time-pressure, states of identity-realization, states of expressing another trait, and transaction-dependent contexts.

In the next step, a different subset of approximately 1,000 responses was extracted from the data set, and five sets of all 1,000 were printed on small cards. Five raters (the first and third authors, along with two undergraduate honors students and one graduate student) independently classified this second subset into the system developed in the earlier stage. Each rater was provided with an instruction sheet including examples and a grid displaying each category name, enabling a visual separation of responses placed in each of the categories. When entered into the data matrix each positive categorization was represented by a 1 , whereas being judged not to fall into the category was represented by a 0 .

The classification decisions were compared using reliability indices. One index was Cohen's kappa coefficient for the paired classifications of the two researchers, for each of the common categories in the classification system. Another index was the average kappa of pairings of the three independent raters, for each category. A third index was the correlation between the assignment proportion (from 0 to 1.0) for the independent raters and that for the researchers. We anticipated that inter-rater agreement indices data could be used to refine the classification system, with the least reliable categories to be discarded as less useable.

Table 3 provides reliability (interjudge agreement) indices - kappa values and correlations between aggregate researcher and rater assignment proportions - for the classification. Clearly, some categories performed better than others. The broad categories of physical locales and relational contexts (associations) led to relatively good consensus in judgments, as did the broad category of activities. For more specific groupings, there was good consensus for two of the subjective state categories (affective/emotive and to a lesser degree goal-realization), but not for other subdivisions of subjective states, indicating our provisional way of subdividing subjective states was less than optimal.

Categories for specific contexts related to sleep, dress, and finance were relatively easy for judges to use with high agreement. In common, these categories involve some observable features. Specific categories with a more purely subjective flavor (e.g., motivational 


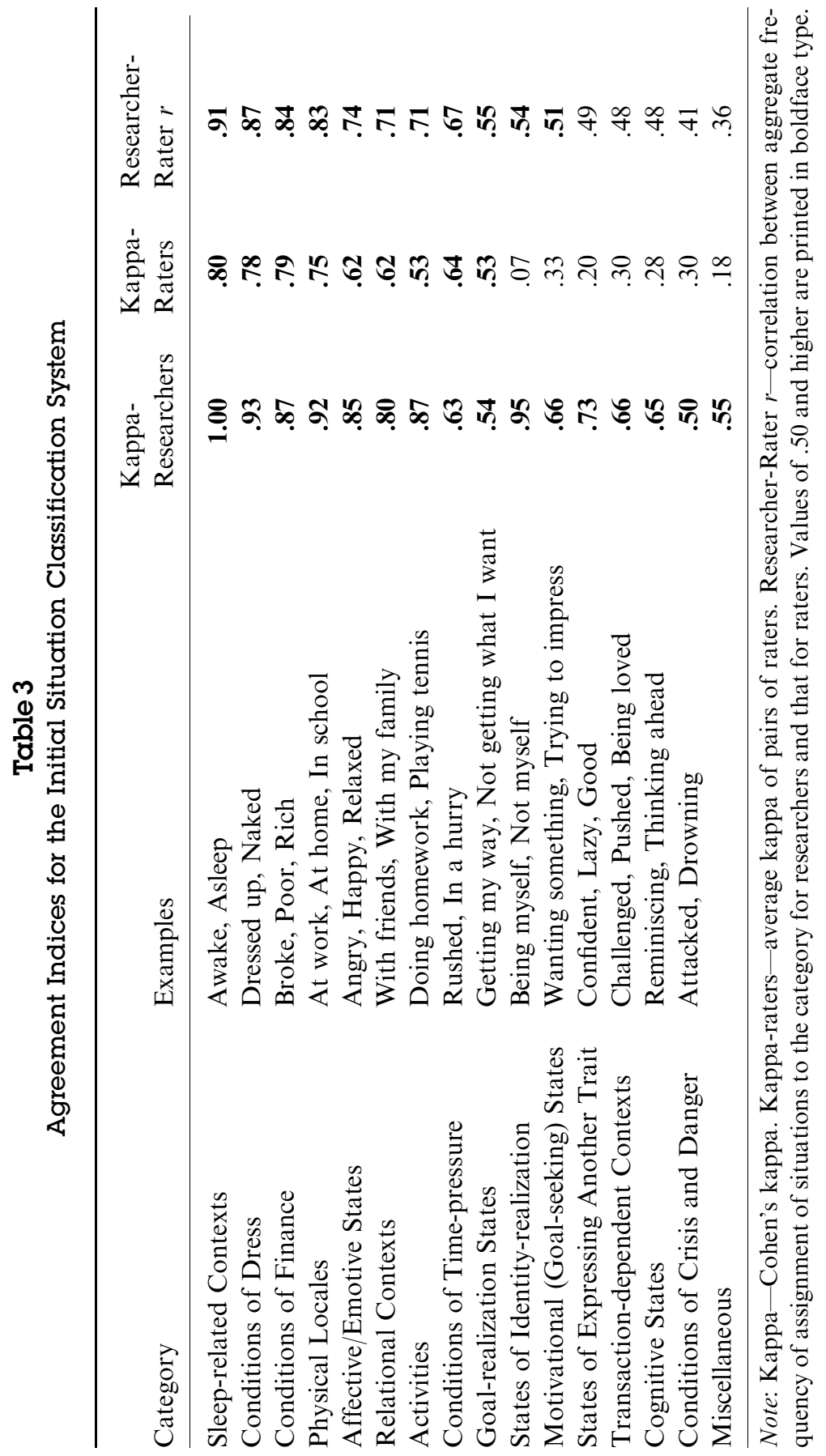


states, cognitive states) were less likely to elicit high agreement. Falling in between these extremes, conditions of time-pressure had a reasonably good degree of agreement.

Overall, 9 of the 16 initial categories had agreement coefficients over .50, even when only the independent judges were considered. Thus, the categorization task supported some of the hypothesized categories. It indicated the reliability of broad Location and Association categories. It provided indications that subcategories of subjective states can be reliable, although some of the provisional subdivisions of this domain did not seem optimal. Results supported another broad, reliable category that was not obvious at the outset (and thus reflected in Table 2): Activities. It also supported specific reliable categories concerned with sleep, dress, and finance.

\section{DISCUSSION}

In our study, a large and useful set of situation descriptions was obtained, and we sought to create categories that seemed the most natural and "indigenous" to this data set. This exercise revealed some important broad categories-including locations, interpersonal associations, and activities - broad categories of situations that might be considered necessary minima for an adequate situation taxonomy. It also revealed some quite specific categories - involving sleep, dress, and finance - that appear to generate reliable classifications quite readily. Delineating the class of Activities accounted for most of the "Actions" in the "Actions and Positions" column in Table 2. Do the residual situations in that column form any additional broad class?

\section{Delineating a Further Domain of Situations}

One important parameter for distinguishing linguistic predicates is a continuum of "control" versus "affectedness" of a participant (Lehmann, 1994). Jumping, for example, is controlled (implying intentionality), whereas falling has a high degree of affectedness. Control versus affectedness is related to distinctions between intentional and unintentional behavior and between controlled and automatic processing. In linguistics, control versus affectedness is used to distinguish between an action and a process. Actions (e.g., doing homework, driving, shopping, cooking) are things one 
makes happen; they involve verbs and place the subject into an agent role. Processes (e.g., in trouble, taken for granted) are things that happen to one; they are uncontrolled by the agent and thus high in affectedness.

If the set of situation classes includes one referencing dynamic states with high agentivity (actions), logically it should also include one referencing dynamic states with high affectedness or passivity, where one is the "patient" and someone or something else is the agent. Thus, this analysis suggests another broad category that we label as "passively experienced processes" or "the press of an external force" (after Murray, 1938). Examples of passively experienced processes are found in the third column of Table 2: rushed, broke, asleep, stressed, challenged, under pressure, and not getting my way. Moreover, one of the more reliable specific categories in our judgment task - Conditions of Time Pressure - seems to be one kind of passively experienced process.

\section{Linguistic Markers for Situation Classes}

The English language has linguistic markers that tend to differentiate between classes of situations. The preposition "at" is a frequent marker for Locations and "with" for Interpersonal Associations. Many other languages have similar prepositions, indeed some languages (e.g., Latin, Sanskrit, Finnish) have a locative case, indicating that situation class is embedded in grammar. The broad category of Activities seems to have a distinct linguistic marker in the gerund, typically having an -ing ending in English. Gerunds are also employed to denote certain subjective states (e.g., reminiscing, being myself, wanting something, feeling a certain way). But the Activities category consists of gerunds indicating an observable or extrinsic behavioral process rather than a subjective state. The category deduced as a contrast to the Activities category-passively experienced processes (or the press of an external force) - also has a distinct linguistic marker in English (-ed).

The association between broad classes of situations and linguistic markers suggests that a lexical rationale for variable selection could be profitably applied to the development of a taxonomy of situations. Necessary minima for a taxonomy of situations might be found by collecting natural-language terms frequently found in English phrases of the following form: 
When or while...

At

With (insert noun denoting object or person, not attribute) ing (insert verb denoting an observable action) ed (insert verb indicating press of an external force)

If one wished also to include subjective states, one could add the following phrasings:

Feeling (insert adjective denoting an attribute)

or wanting) ing (insert verb denoting a kind of thinking, feeling,

The same approach might be employed in other languages as well, with adaptation to analogous linguistic markers (whether prepositions, gerunds, or suffixed word endings like those here, or something different). This lexical approach provides a much broader form of a lexical approach to situations compared to that of Van Heck (1984), who sought out nouns that could fit into a sentence stem like "Being in a/the situation."

\section{Relation to Previous Studies}

Usually when we think about situations, especially from a personality standpoint, we answer one or more of the following questions, some of which were suggested by Pervin (1978): Where am I? Who am I with? What am I doing (or trying to do)? What is happening to or being done to me? Each of these questions, we suggest, leads to its own domain of situational states. A complete taxonomy of situations would include ways of answering any or all of these questions.

In our introduction, we noted three levels of situation features: environmental/physical, canonical/consensual, and functional/subjective. These levels have interesting relations with our proposed situation domains. Locations can be considered a prime type of environmental/physical features, although commonly mentioned locations (e.g., work, home, school, party) have a canonical aspect as well. Associations (e.g., with friends or family) highlight canonical features. Subjective states, if they are considered situations, highlight some of the functional features of situations. Actions (or activities) are partly functional/subjective (because the agent best knows the intent of the action) and partly canonical (because many actions 
have a consensual definition-these are to a degree shared scripts that acquire a conventional label). The domain of passively experienced processes seems also to combine subjective and canonical features. Further, we noted in the introduction that these three levels can be differentiated on the basis of observability versus subjectivity. Locations and associations are high on observability, activities often are, and passively experienced processes sometimes are. Subjective states are, of course, notably low on observability.

Our proposed domains can be related to several previous classifications (Cantor et al., 1982; Magnusson, 1971; Pervin, 1978; Van Heck, 1984, 1989). Locations have the selfsame label in the Pervin and Van Heck classifications, but are labeled "settings" in those by Magnusson and Shoda et al. Associations correspond to the "people" situation types from three of the classifications (Pervin, 1978; Cantor et al., 1982; Van Heck, 1984, 1989). Actions are variously labeled as actions, activities, or behavior in the same three models. Subjective states come closest to "feelings and traits" situation type from Cantor et al., but are also represented in the Shoda et al. classification.

However, there is no obvious counterpart among our proposed domains for some of the situation types in previous classifications: context (of an institutional/historical sort; Van Heck), atmosphere (general mood of a physical situation; Cantor et al.), objects (that enable certain behaviors; Van Heck), and times (Pervin) or temporal aspects (Van Heck). This should serve as a reminder that there may be situation types falling outside the domains we propose, and suggest directions for potential supplementation and revision. In particular, a review of the situations found effectual in experimental social psychology may reveal effects of context, atmosphere, objects, and times of which laypersons tend not to be aware.

\section{Can a Subjective State Be Considered a Situation?}

Subjective states involving mood were frequently mentioned as modifiers of personality tendencies. This is surprising. Psychologists have become accustomed to thinking of "emotions" as a domain of variables that is separate from situations. However, our participants indicated that their behavior pattern often was altered when their mood was altered. Other motivational or internal states were mentioned at a lower rate than were those related to mood and emotion. Clearly, mood states are quite salient in laypersons' views of what 
influences their traits. Moreover, some important classes of variables (e.g., defense and coping styles) are dispositions arising in the context of specific mood states (e.g., how one reacts when anxious or stressed). And the manipulability of mood states, by way of mood induction, appears to provide some similarity between subjective states and more typical situational variables.

However, the tendency to mention subjective states as if they were situations might be explained in other ways. It may stem more from the high experiential salience of these states than from their real effects on behavioral trait expression. Respondents may have been overgeneralizing: "when I'm angry" might be interpreted to mean "when occurs any of a wide variety of situations, having in common that they evoke an angry response in me." It may stem from laypersons confusing situational and dispositional causes. As Murray (1938) implied, people might confuse effects on a subject (e.g., being insulted) and responses by that subject (e.g., feeling angry); for Murray, responses were not part of press, not even of "beta press"the subjective interpretation of the situation. Moreover, laypersons often do not know the real causes of their behavior (e.g., Nisbett \& Wilson, 1977), and may improvise by mentioning aspects of their experience that are particularly salient (but not real causes). And, subjective states might also be put in a separate category from dispositions and situations. They might be considered epiphenomena of various dispositional and situational causes. Alternatively, as an interface between the motivated organism and its environment that reflects whether "things are going my way or not," subjective states may serve as indicators that a goal state and a situation are either congruent or incongruent (Carver \& Scheier, 1990), rather than being directly causal. If subjective states are truly epiphenomena, we might ignore them. If they do have causal effects, being at home in neither category, they may deserve their own category.

Therefore, it seems reasonable to exclude subjective states from a situation taxonomy. Researchers interested only in prototypical situations should confine themselves to situation variables on the left side of Table 2. It will be useful, however, to continue studying subjective states alongside more prototypical situational variables, comparing them for example with respect to the magnitude of their causal influence. Situations and subjective states might be two important and complementary classes of non-dispositional behavior explanations. 


\section{Limitations}

The situation domains we have delineated are unlikely to be totally comprehensive of situation domains. Two of the frequent responses listed in Table 2-in charge/control and right (or wrong) - do not fit into any of the domains, although their commonality suggests that momentary social positioning could be a further domain, linguistically distinguishable as responses that might fit well into the sentence "When I am the one who is

Situations are fluid and complex and will often be difficult to describe in a single word or phrase in the way that participants were prompted to do in this study. In some cases, a situation will be better described by a combination of the situation domains delineated here. In other cases, only a more detailed phenomenological approach will capture the complex nature of a situation. A different methodology may be needed to capture the more complex aspects of situations.

We make no assumption that all categories will be equally relevant for all kinds of traits and attributes. Our focus here was limited to delineating across-trait patterns with regard to situations, and we leave the discerning of between-trait differences to future studies.

Our sample, although rather diverse with respect to ethnicity and age, was not large in size and was limited to college students. Results might differ to some degree if participants were from another culture or an overall older age group. Indeed, it might prove quite edifying to repeat the procedures used here in other samples.

Finally, our empirical study was based on layperson language, and reflects the preoccupations of laypersons as well as any of their biases. It shows what laypersons think are important situations. As we noted at the outset, it would be useful to supplement this lay account with a survey of the important situational effects discernible in experimental social psychology; such a survey might compensate for major blind spots in lay perception of situational influences.

\section{CONCLUSIONS}

The present studies elicited situation descriptions that would be relevant to the expression (or suppression) of personality attributes. Based on these descriptions we arrived at some empirically derived categories. In our results, Locations and Associations were easily 
delineated categories within which situation dimensions might be found, and further examination suggested additional categories of Activities and Passively Experienced Processes.

The previous literature on a taxonomy of situations has identified useful categorical distinctions for such a taxonomy. The empirically derived categories from our study bear strong but not always perfect relations to those developed in the previous literature. We stress that our study does not lead directly to dimensions of situations, but operates at a broader level, identifying domains of situations that are closely aligned with the situation levels identified by Block and Block (1981). Although one might be tempted to label such domains as something analogous to a "Big Five" of situations, this would not be an apt comparison. Our domains are not dimensions of interindividual variation, but rather categories of variables within which one might find as yet undiscovered dimensions (which may resemble those found by ten Berge and De Raad, 2001, 2002). The Big Five are dimensions found within the single category of personality-trait variables, but there are other categories (domains) besides traits (e.g., abilities, attitudes and beliefs, interests) that have their own subsidiary dimensions, and these categories (domains) are more analogous to the situation domains proposed here.

These domains can help provide the basis for a comprehensive situation taxonomy that could be used by trait, interactionist, and socio-cognitive personality psychologists, and by any who are interested in behavior dynamics. From the viewpoint of Mischel and Shoda's model of intra-individual personality functioning, the currently proposed domains delineate general categories within the "encoding" level that incorporate situation features. Such a taxonomy increases the pace towards a Unified Theory of Personality (Funder, 2001), an important goal of personality science.

\section{REFERENCES}

Bem, D., \& Funder, D. C. (1978). Predicting more of the people more of the time: Assessing the personality of situations. Psychological Review, 85, 485-501.

Block, J., \& Block, J. (1981). Studying situational dimensions: A grand perspective and some limited empiricism. In D. Magnusson (Ed.), Toward a psychology of situations: An interactional perspective (pp. 85-106). Hillsdale, NJ: Erlbaum.

Bowers, K. S. (1973). Situationism in psychology: An analysis and a critique. Psychological Review, 80, 307-336. 
Buss, D. M., \& Craik, K. H. (1983). The act frequency approach to personality. Psychological Review, 90, 105-126.

Cantor, N., Mischel, W., \& Schwartz, J. (1982). A prototype analysis of psychological situations. Cognitive Psychology, 14, 45-77.

Carver, C. S., \& Scheier, M. F. (1990). Origins and functions of positive and negative affect: A control-process view. Psychological Review, 97, 19-35.

Endler, N. S. (1993). Personality: An interactional perspective. In P. J. Hettema \& I. J. Deary (Eds.), Foundations of personality (pp. 251-268). Dordrecht, Netherlands: Kluwer.

Endler, N. S., \& Magnusson, D. (1976). Interactional psychology and personality. Washington, DC: Hemisphere.

Endsley, M. R. (1995). Toward a theory of situation awareness. Human Factors, 37, 32-64.

Forgas, J. P., \& Van Heck, G. L. (1992). The psychology of situations. In G. V. Caprara \& G. L. Van Heck (Eds.), Modern personality psychology: Critical reviews and new directions (pp. 418-455). New York: Harvester Wheatsheaf.

Frederiksen, N. (1972). Toward a taxonomy of situations. American Psychologist, 27, 114-123.

Funder, D. C. (2001). Personality. Annual Review of Psychology, 52, 197-221.

Funder, D. C., \& Colvin, C. R. (1991). Explorations in behavioral consistency: Properties of persons, situations, and behaviors. Journal of Personality and Social Psychology, 60, 773-794.

Furnham, A., \& Argyle, M. (1981). The psychology of social situations: Selected readings. Oxford, UK: Pergamon Press.

Hogan, R., Harkness, A. R., \& Lubinski, D. (2000). Personality and individual differences. In K. K. Pawlik \& M. R. Rosenzweig (Eds.), International handbook of psychology (pp. 283-304). London: Sage.

Ickes, W. A., Snyder, M., \& Garcia, S. (1997). Personality influences on the choice of situations. In J. A. Johnson \& R. Hogan (Eds.), Handbook of personality psychology (pp. 165-195). San Diego, CA: Academic Press.

John, O. P. (1990). The "Big Five" factor taxonomy: Dimensions of personality in the natural language and in questionnaires. In L. A. Pervin (Ed.), Handbook of personality: Theory and research (pp. 66-100). New York: Guilford.

Johnson, J. A. (1999). Old wine in new bottles. European Journal of Personality, 13, 443-453.

Kantor, J. R. (1924). Principles of psychology (Vol. 1.). Bloomington, IL: Principia.

Koffka, K. (1935). Principles of Gestalt psychology. New York: Harcourt.

Lehmann, C. (1994). Predicates: Aspectual types. In R. E. Asher (Ed.), The encyclopedia of language and linguistics (Vol. 1, pp. 3297-3302). Oxford, UK: Pergamon.

Lewin, K. (1936). Principles of topological psychology. New York: McGraw-Hill.

Magnusson, D. (1971). An analysis of situational dimensions. Perceptual and Motor Skills, 32, 851-867.

Magnusson, D. (1981). Toward a psychology of situations: An interactional perspective. Hillsdale, NJ: Erlbaum. 
Magnusson, D., \& Ekehammer, B. (1976). Perceptions of and reactions to stressful situations. In N. S. Endler \& D. Magnusson (Eds.), Interactional psychology and personality (pp. 547-559). Washington, DC: Hemisphere.

Mischel, W., \& Shoda, Y. (1999). Integrating dispositions and processing dynamics within a unified theory of personality: The Cognitive Affective Personality System (CAPS). In L. A. Pervin \& O. P. John (Eds.), Handbook of personality: Theory and research (2nd ed., pp. 197-218). New York: Guilford.

Murray, H. A. (1938). Explorations in personality. New York: Oxford University Press.

Nisbett, R. E., \& Wilson, T. D. (1977). Telling more than we can know: Verbal reports on mental processes. Psychological Review, 84, 231-259.

Pervin, L. A. (1978). Definitions, measurements, and classifications of stimuli, situations, and environments. Human Ecology, 6, 71-105.

Revelle, W. (1995). Personality processes. Annual Review of Psychology, 46, 295-328.

Saucier, G. (1997). Effects of variable selection on the factor structure of person descriptors. Journal of Personality and Social Psychology, 73, 1296-1312.

Sells, S. B. (1963). An interactionist looks at the environment. American Psychologist, 18, 696-702.

Shoda, Y., Mischel, W., \& Wright, J. C. (1994). Intraindividual stability in the organization and patterning of behavior incorporating psychological situations into the idiographic analysis of personality. Journal of Personality and Social Psychology, 67, 674-687.

Snyder, M. (1983). The influence of individuals on situations: Implications for understanding the links between personality and social behavior. Journal of Personality, 51, 497-516.

ten Berge, M. A., \& De Raad, B. (1999). Taxonomies of situations from a trait psychological perspective: A review. European Journal of Personality, 13, 337-360.

ten Berge, M. A., \& De Raad, B. (2001). The construction of a joint taxonomy of traits and situations. European Journal of Personality, 15, 253-276.

ten Berge, M. A., \& De Raad, B. (2002). The structure of situations from a personality perspective. European Journal of Personality, 16, 81-102.

Van Heck, G. L. (1984). The construction of a general taxonomy of situations. In H. Bonarius, G. Van Heck, \& N. Smid (Eds.), Personality psychology in Europe: Theoretical and empirical developments (pp. 149-164). Lisse, Netherlands: Swets \& Zeitlinger.

Van Heck, G. L. (1989). Situation concepts: Definitions and classifications. In P. J. Hettema (Ed.), Personality and environment: Assessment of human adaptation (pp. 53-69). Oxford, England: John Wiley.

Van Heck, G. L., Perugini, M., Caprara, G. V., \& Froeger, J. (1994). The Big Five as tendencies in situations. Personality \& Individual Differences, 16, 715-731.

Van Mechelen, I., \& De Raad, B. (1999). Editorial: Personality and situations. European Journal of Personality, 13, 333-336.

Wright, J. C., \& Mischel, W. (1987). A conditional approach to dispositional constructs: The local predictability of social behavior. Journal of Personality and Social Psychology, 53, 1159-1177.

Zwaan, R. A., \& Radvansky, G. A. (1998). Situation models in language comprehension and memory. Psychological Bulletin, 123, 162-185. 


\section{4}

